\title{
Correction to: Pathophysiology of and therapeutic options for a GABRA1 variant linked to epileptic encephalopathy
}

Yun-Fei Bai ${ }^{1,2+}$, Michelle Chiu ${ }^{3 \dagger}$, Elizabeth S. Chan ${ }^{1 \dagger}$, Peter Axerio-Cilies ${ }^{1}$, Jie Lu' ${ }^{1}$, Linda Huh ${ }^{3}$, Mary B. Connolly ${ }^{3}$, Ilaria Guella ${ }^{4}$, Matthew J. Farrer ${ }^{4,5}$, Zhi-Qing David $\mathrm{Xu}^{2}$, Lidong Liu ${ }^{1 *}$, Michelle Demos ${ }^{3^{*}}$ and Yu Tian Wang ${ }^{1 *}$

\section{Correction to: Mol Brain (2019) 12:92 \\ https://doi.org/10.1186/s13041-019-0513-9}

Following publication of the original article [1], the authors reported errors in Fig. 4. Specifically, a wrong actin blot is presented in Fig. 4a. In this Correction, the corrected version of Fig. 4 is shown.

\begin{abstract}
Author details
'Djavad Mowafaghian Centre for Brain Health and Department of Medicine, University of British Columbia, Vancouver, Canada. ${ }^{2}$ Department of Neurobiology, Beijing Key Laboratory of Neural Regeneration and Repair, Beijing Laboratory of Brain Disorders (Ministry of Science and Technology), Beijing Institute for Brain Disorders, Capital Medical University, Beijing, China. ${ }^{3}$ Division of Neurology, Department of Paediatrics, BC Children's Hospital, University of British Columbia, Vancouver, Canada. ${ }^{4}$ Centre for Applied Neurogenetics, University of British Columbia, Vancouver, Canada. ${ }^{5}$ McKnight Brain Institute, University of Florida, Gainesville, USA.
\end{abstract}

Published online: 27 March 2020

\section{Reference}

1. Bai YF, et al. Pathophysiology of and therapeutic options for a GABRA1 variant linked to epileptic encephalopathy. Mol Brain. 2019;12:92. https://doi. org/10.1186/s13041-019-0513-9.

The original article can be found online at https://doi.org/10.1186/s13041019-0513-9

*Correspondence: lidong@mail.ubc.ca; mdemos@cw.bc.ca;

ytwang@brain.ubc.ca

${ }^{T}$ Yun-Fei Bai, Michelle Chiu and Elizabeth S. Chan contributed equally to this work.

'Djavad Mowafaghian Centre for Brain Health and Department of Medicine, University of British Columbia, Vancouver, Canada

${ }^{3}$ Division of Neurology, Department of Paediatrics, BC Children's Hospital, University of British Columbia, Vancouver, Canada

Full list of author information is available at the end of the article

(c) The Author(s). 2020 Open Access This article is licensed under a Creative Commons Attribution 4.0 International License, which permits use, sharing, adaptation, distribution and reproduction in any medium or format, as long as you give appropriate credit to the original author(s) and the source, provide a link to the Creative Commons licence, and indicate if changes were made. The images or other third party material in this article are included in the article's Creative Commons. licence, unless indicated otherwise in a credit line to the material. If material is not included in the article's Creative Commons licence and your intended use is not permitted by statutory regulation or exceeds the permitted use, you will need to obtain permission directly from the copyright holder. To view a copy of this licence, visit http://creativecommons.org/licenses/by/4.0/. The Creative Commons Public Domain Dedication waiver (http://creativecommons.org/publicdomain/zero/1.0/) applies to the data made available in this article, unless otherwise stated in a credit line to the data. 


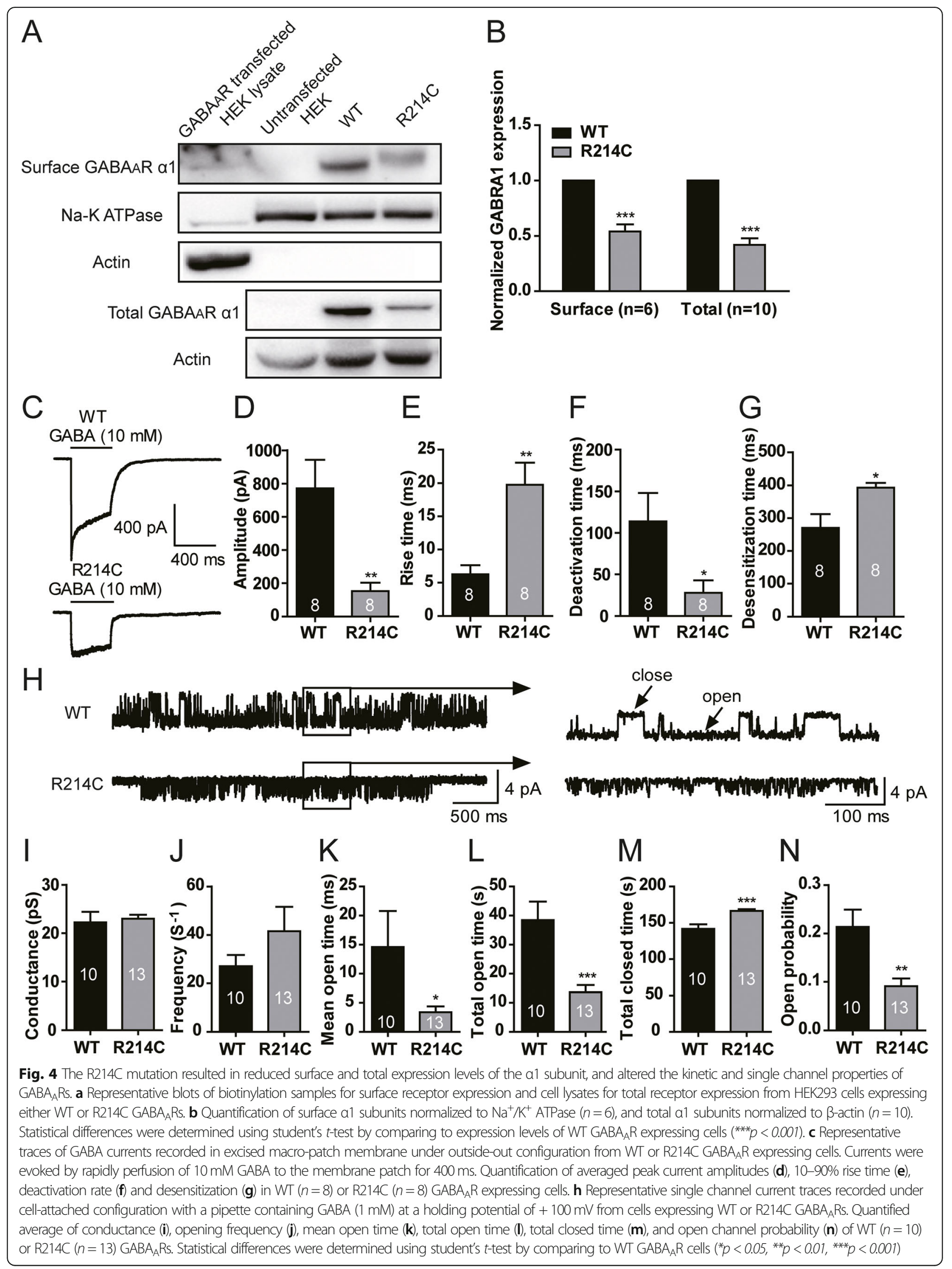

